\title{
Minimally invasive intrasulcular tunneling technique for treatment of gingival recessions- Case Series
}

Dler Khursheed ${ }^{1}$ and Faraedon Zardawi ${ }^{1}$

${ }^{1}$ University of Sulaimani

August 30, 2021

\begin{abstract}
Modification of coronally advanced flap (CAF) by tunneling procedure was applied on four cases of gingival recession. Postoperative follow up, at different time breaks recorded full coverage of almost all receded root surfaces. The technique and the clinical outcome of this technique will be demonstrated in this case series report.
\end{abstract}

Minimally invasive intrasulcular tunneling technique for treatment of gingival recessions- Case Series

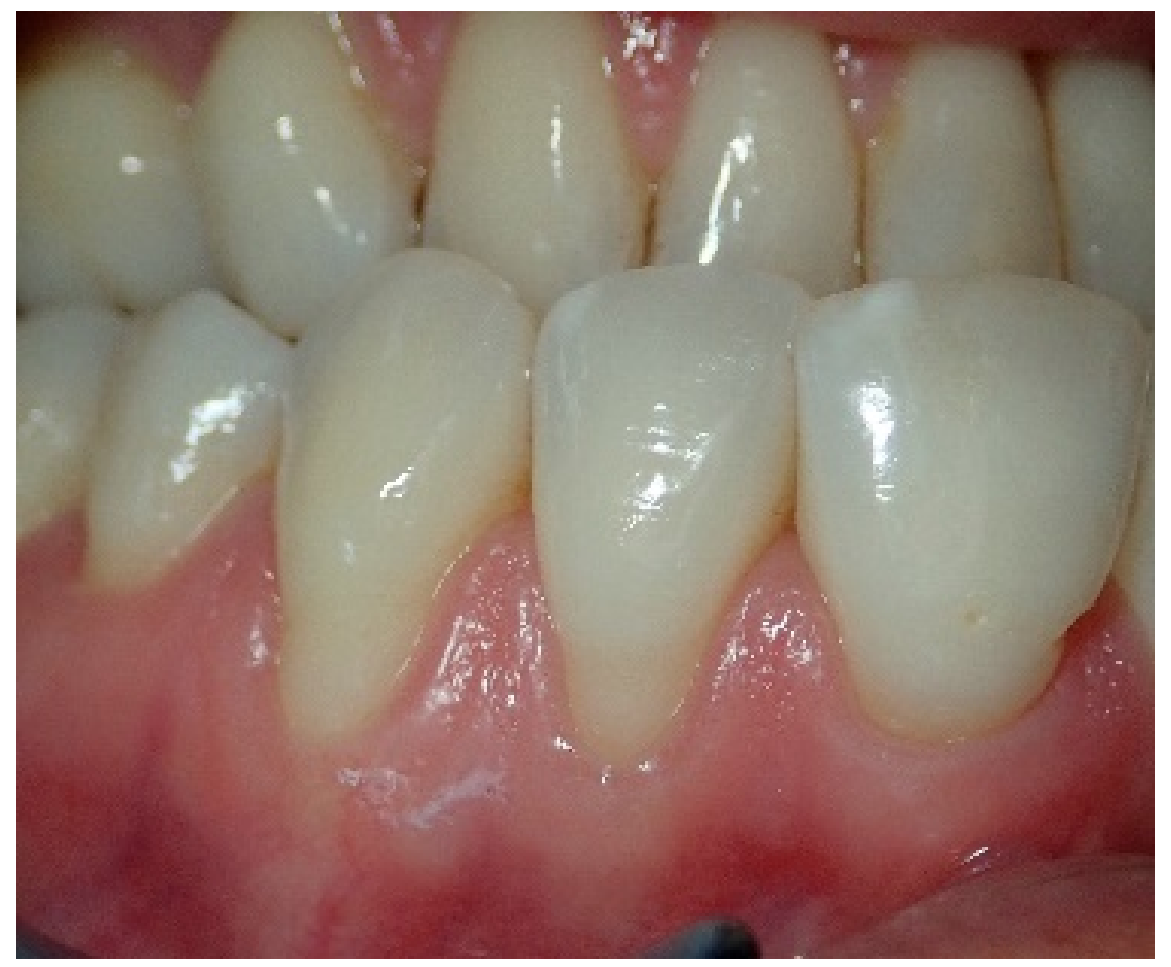

\section{Abstract:}

Modification of coronally advanced flap (CAF) by tunneling procedure was applied on four cases of gingival recession. Post-operative follow up, at different time breaks recorded full coverage of almost all receded root 
surfaces. The technique and the clinical outcome of this technique will be demonstrated in this case series report.

Keywords: Advanced flap, tunneling procedure, connective tissue graft, modification of tunneling.

\section{Background}

Localized or generalized location of gingival margin apical to cementoenamel junction (CEJ) under different circumstances and etiologic backgrounds called gingival recession. ${ }^{(1,2)}$ These causing decisive problems such as esthetic, phonetics, impeding plaque control by pulling the gingival margin and hypersensitivity. ${ }^{(3)}$ These problems often call for either surgical or nonsurgical treatment. The ultimate goal of surgical procedures is to achieve complete and predictable root coverage. ${ }^{(2)}$ Several surgical approaches have been accredited for root coverage, ${ }^{(4)}$ including free gingival graft (FGG) and, connective tissue grafts (CTG) in combination with different flap designs. (5-7) Coronally advanced flap (CAF) combined with CTG is considered the effective root coverage procedure. ${ }^{(7)}$ Further, CAF could also be performed without vertical incisions and gingival papillary involvement, which is called tunneling procedure (TUN). $\left.{ }^{8}, 9\right)$ Surgical tunneling procedure may be accomplished with combined partial and full thickness flap; however, full thickness flap may be appropriate especially for thin gingival biotypes. $(6,8)$ Flap tension should also be minimized to enhance both flap and stability over the denuded roots. (10) Flap undermining and muscle dissection are essential for immobilization of the graft. ${ }^{(11)}$ Therefore, this case series aimed to present the predictability of covering recession with intrasulcular tunneling preparation by extension of the flap further laterally and apically using single tunneling instrument and modification of CTG placement by laterally stretched suturing technique.

\section{Clinical presentation:}

In addition to demographic data, the following clinical measurements were taken to determine recession types (RT). ${ }^{(12)}$ Width and length of recessions, clinical attachment level (CAL), vestibular depth from apical extent of the recessions, gingival biotype reference and further, presence or absence of CEJ \pm cervical lesions and tooth mobility were recorded for each individual recession (Table 1).

All patients were systemically and periodontally fit for the surgery, surgical procedures were performed by one, well skilled periodontist. Details of the surgery and their possible complications were explained to the patients, and signed informed consent was taken from them before proceeding surgical procedures. Further, the study proposal was applied to the scientific committee of the college of dentistry, University of Sulaimani for registration and obtaining ethical approval for undertaking this study.

\section{Case Management}

Root surface debridement was performed with a curette after giving local anesthetics to the area by infiltration. Tunneling was performed using a Hu-friedy tunneling knife (TKN1 \#1 HDL \#6) and a fine tissue separator (Dentag Evo) (Figure 1). The procedure was performed by separating the gingival flap and vestibular mucosal tissues from underling bone and muscular tissues, respectively. Separation and entire tunneling preparation was carried out with single tunneling instrument without using microblade for sulcular incision. Tunneling started from margins of the recession, extended laterally to mid-facial line of the adjacent teeth at level of facial CEJ, and extended further apically to minimize tension from underline muscles (Figure 2b).

The graft was passed under the tunnel and sutured from either side. The original technique was modified in the current study by retaining the graft with 2 circular stitches around adjacent teeth or with composite filling. This will hold part of the graft fixed over the receded roots and the other part over the underlying bone, without being sutured to the flap, to retain the graft fixed in place and avoid dislodgment under possible tension. In multiple recession cases, free gingival flap margin was sutured independently and fixed by composite filling to the facial surfaces of teeth (Figures 2c). The palatal wound was dressed using hemostatic sponge and fixed by sutures.

\section{Clinical outcomes:}


The study included 3 cases, two cases were single gingival recession (RT2), Figures (3a-3j) and Figures (4a4c), and the third case was two multiple recessions on the upper, Figures (5a-5f) and lower teeth Figures (6a-6c); all recessions recorded as RT1 except for \#21 and 31 were recorded as RT2 Table 1 . The recessions were measured at different follow up times postoperatively. Complete root coverage was achieved on total 8 recessions involved in this study Table 1 .

\section{Discussion:}

The incision free design and gingival papillary preservation are considered as the main advantages of TUN. ${ }^{(8)}$ In the current study sufficient tissue was undermined with minimum papillary involvement around the recession area ${ }^{(9)}$ to release active tension from surrounding tissues and approximate gingival recession margins over the CTG. These would also lead to increase blood supply to that part of the graft on the exposed root as it does not get blood supply from underline exposed root. ${ }^{(12)}$ Furthermore, the remaining part of the graft under the tunnel gets dual blood supply from the underlying periosteum and overlying subepithelial connective tissue respectively. This will avoid necrosis of the free graft tissue over the denuded root surface by providing dual nutrition for the graft.

The major design modification of the flap was further extension of the flap on both side and the apical side to provide a relaxed bed for the graft. Therefore, a modification in tissue preparation and CTG suturing may add some advantages to the stability of the graft in term of mechanical and biological aspects. In this procedure, the CTG is completely secured by starching is laterally and sutured around the teeth adjacent to the recession on both sides without being sutured to the underlying periosteum and/or overlying flap tissue. In this condition the graft is kept fixed with no shrinkage and better survival rate. Stretching the graft avoid shrinkage and make the graft better responsive to revascularization, ${ }^{(11,13,14)}$. The only limitation of applying this technique is when thin gingival biotype is present that makes the tunneling preparation with partial thickness flap is difficult (Table 2).

Higher predictability rate of the clinical outcome could be expected with the current modification, while the tunnel flap and the graft are relaxed and not under tension to avoid any mobility of the graft that compromises the normal healing process.

Acknowledgment: The authors acknowledge the staff of department of Periodontics for their kind help and support for fulfilling the surgical procedures

Conflict of interest: No conflict of interest was declared by the authors of this study

Author contribution: DK. Design and Case documentation, FZ. Manuscript preparation, and final approval of the manuscript.

Key Clinical message: Coronally advanced flap (CAF) by tunneling procedure is considered one of the effective root coverage procedures particularly when it is combined with CTG. Modification of the conventional technique. Post-operative follow up, at different time breaks recorded full coverage of almost all receded root surfaces.

\section{References}

1. Periodontology AAo. Glossary of periodontal terms: American Academy of Periodontology; 2001.

2. Slutzkey S, Levin L. Gingival recession in young adults: occurrence, severity, and relationship to past orthodontic treatment and oral piercing. American Journal of Orthodontics and Dentofacial Orthopedics. 2008;134(5):652-6.

3. Imano M, Spada PP, Macalossi JMS, Deliberador TM. Treatment of Localized Gingival Recession by Means Tunnel Technique after the Orthodontic Treatment. A Follow-Up of 1 Year. Case Reports in Dentistry. 2020;2020.

4. Zuhr O, Fickl S, Wachtel H, Bolz W, Hurzeler M. Covering of gingival recessions with a modified microsurgical tunnel technique: case report. International Journal of Periodontics and Restorative Dentistry. 
2007;27(5):457.

5. Pradeep K, Rajababu P, Satyanarayana D, Sagar V. Gingival recession: review and strategies in treatment of recession. Case reports in dentistry. 2012;2012.

6. Sculean A, Allen EP. The Laterally Closed Tunnel for the Treatment of Deep Isolated Mandibular Recessions: Surgical Technique and a Report of 24 Cases. International Journal of Periodontics \& Restorative Dentistry. 2018;38(4).

7. Wessel JR, Tatakis DN. Patient outcomes following subepithelial connective tissue graft and free gingival graft procedures. Journal of periodontology. 2008;79(3):425-30.

8. Wang Y, Stathopoulou PG. Tunneling Techniques for Root Coverage. Current Oral Health Reports. 2019;6(4):237-43.

9. Zabalegui I, Sicilia A, Cambra J, Gil J, Sanz M. Treatment of multiple adjacent gingival recessions with the tunnel subepithelial connective tissue graft: a clinical report. International Journal of Periodontics \& Restorative Dentistry. 1999;19(2).

10. Pini Prato G, Pagliaro U, Baldi C, Nieri M, Saletta D, Cairo F, et al. Coronally advanced flap procedure for root coverage. Flap with tension versus flap without tension: A randomized controlled clinical study. Journal of Periodontology. 2000;71(2):188-201.

11. Shkreta M, Atanasovska-Stojanovska A, Dollaku B, Belazelkoska Z. Exploring the gingival recession surgical treatment modalities: A literature review. Open access Macedonian journal of medical sciences. 2018;6(4):698.

12. Cairo F, Nieri M, Cincinelli S, Mervelt J, Pagliaro U. The interproximal clinical attachment level to classify gingival recessions and predict root coverage outcomes: an explorative and reliability study. Journal of clinical periodontology. 2011;38(7):661-6.

13. Miller Jr P. Regenerative and reconstructive periodontal plastic surgery. Mucogingival surgery. Dental Clinics of North America. 1988;32(2):287-306.

14. Holbrook T, Ochsenbein C. Complete coverage of the denuded root surface with a one-stage gingival graft. The International journal of periodontics \& restorative dentistry. 1983;3(3):8-27.

\section{Figure Legends:}

1. Figure 1: Surgical instrument applied for tunneling procedure

2. Figure 2: Schematic illustration of modified tunneling procedure; preoperative state (a), dotted lines indicate extensions of the flap, placement of CTG (b), graft is sutured around adjacent teeth, the flap is further advanced coronally, sutured and fixed with composite filling (c), Root coverage postoperatively (d).

3. Figure 3, Pre-operative view RT2 (a), measurement of recession length and width (b\&c), extension of the tunnel laterally (d), de-epithelized free connective tissue graft (e), placement of the graft and sutured laterally (f), advancing the recession margins to cover the exposed graft (g), the donor graft area is sutured with hemostatic sponge (h), CRC two weeks and 13 months postoperatively (i \&j).

4. Figure 4: Pre-operative view RT1 (a), $3 \mathrm{~mm}$ gingival recession (b), complete root coverage after 2 months (c).

5. Figure 5: RT1 on teeth \# 42 and 43 (a), each had $3 \mathrm{~mm}$ recession (b and c), suturing the flap over the graft (d), complete root coverage after 2 weeks (f), healthy and stable gingiva after 3 months (g).

6. Figure 6: RT2 on teeth \#21,31 and RT1 on teeth \#22,32 (a), complete root coverage after 2 weeks (b), stable tissue after 2 months (c). 

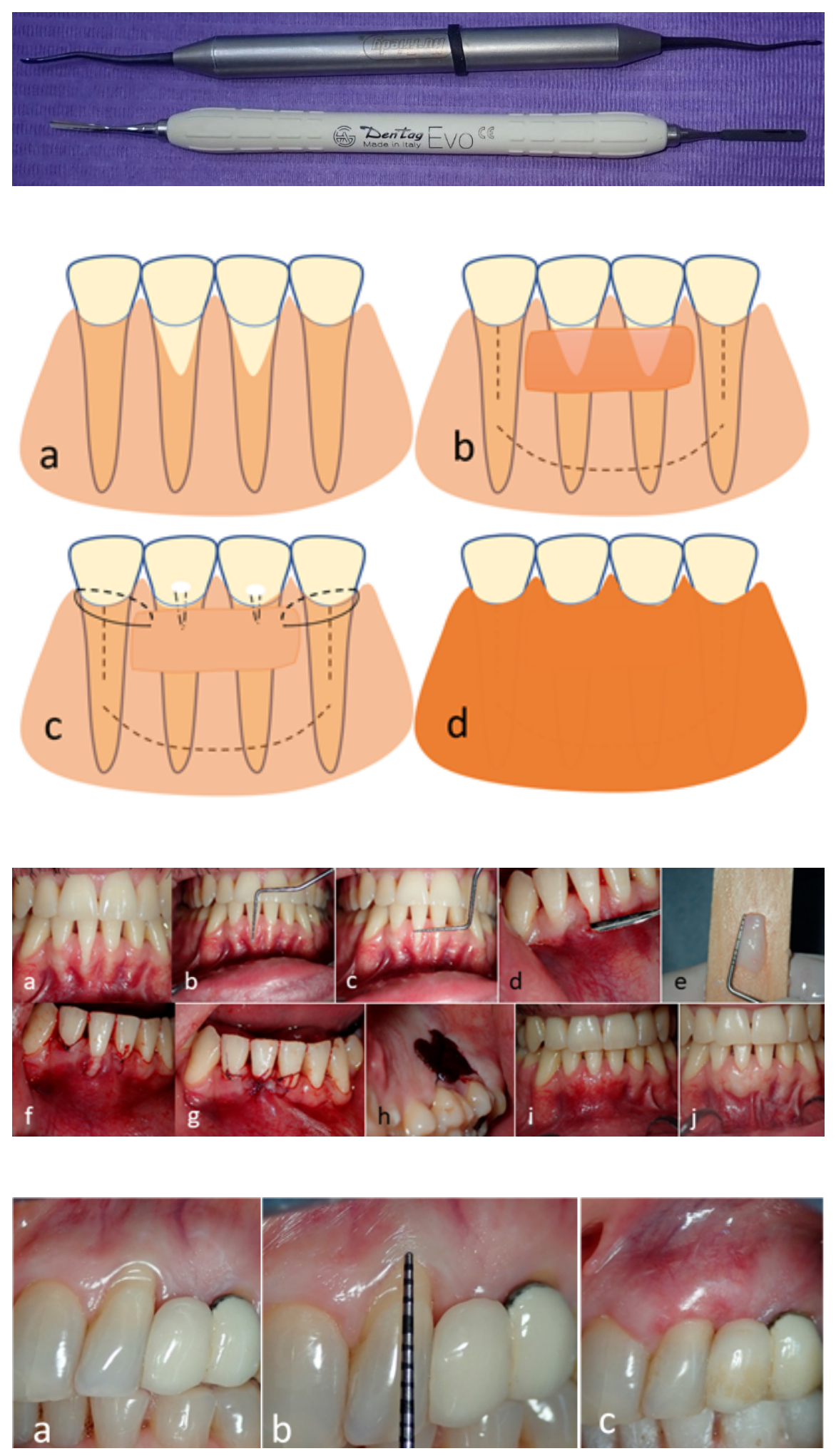

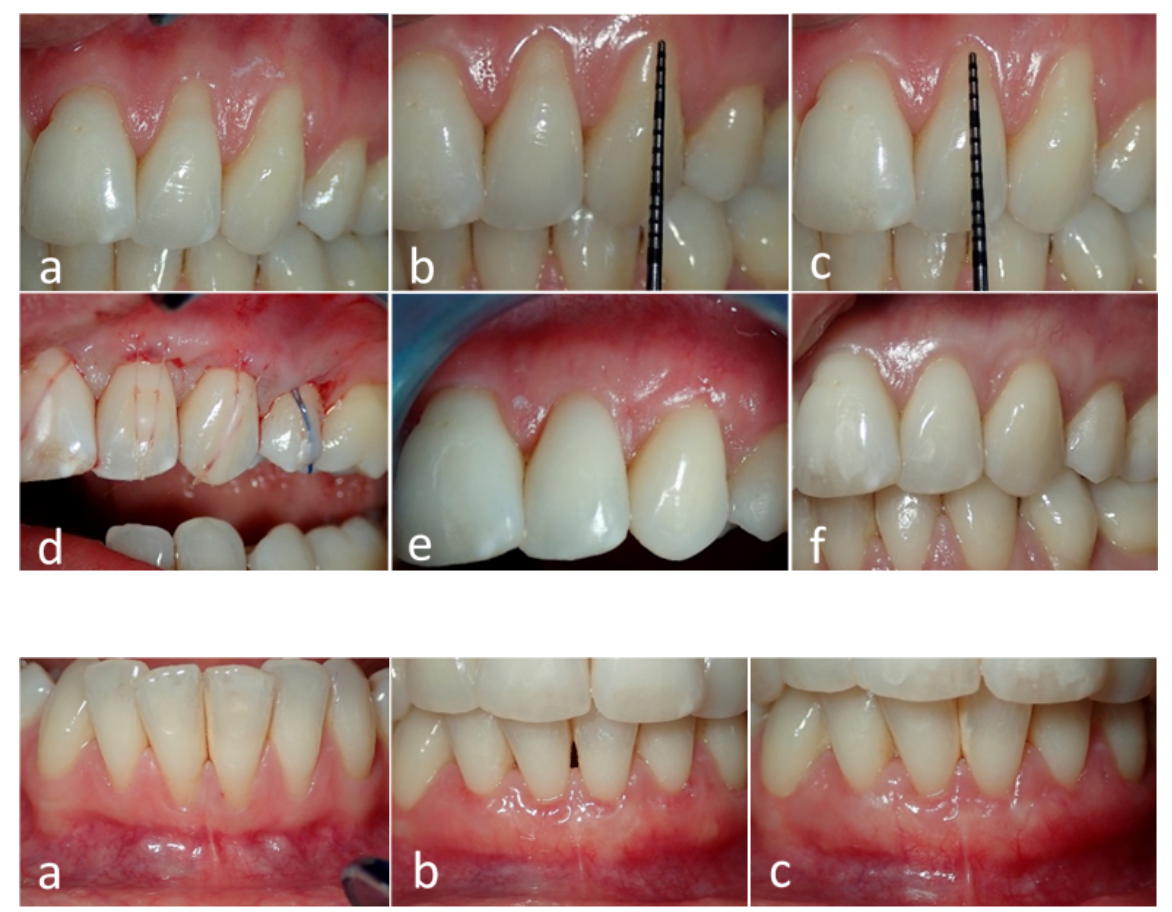